\title{
DFT analysis elementary reaction steps of catalytic activity for ORR on metal-, nitrogen- co-doped graphite embedded structure
}

\author{
Yi Xiao $^{1}$ (D) Weibin Zhang $^{2}$
}

Received: 31 October 2019 / Accepted: 8 January 2020 / Published online: 11 January 2020

(c) Springer Nature Switzerland AG 2020

\begin{abstract}
Metal-nitrogen coordinated graphite coordination structures are becoming more and more attractive for its novel catalytic activity in oxygen reduction reaction (ORR) at the fuel cells. In this work, single copper atom on graphitic carbon nitride acting as electrocatalyst for ORR have been investigated by using the density functional theory method. Our study results that the $\mathrm{Cu}$ site is the active center for all the possible elementary steps of the ORR. Further studies the elementary reaction steps are used to explore the underlying mechanisms to gain insights into ORR. Both the $\mathrm{O}_{2}$ dissociation and $\mathrm{O}_{2}$ hydrogenation paths are probably to ORR on the $\mathrm{CuN}_{4}$-Gra surface. All the possible elementary reaction steps for the $\mathrm{ORR}$ are exothermic with small reaction barriers (less than $1.98 \mathrm{eV}$ ) for $\mathrm{O}_{2}$ hydrogenation. Meanwhile, with large reaction barrier $(3.16 \mathrm{eV})$ for $\mathrm{O}_{2}$ dissociation to go through the rate-limiting steps. The Gibbs free energy for each elementary step of ORR is used to clarify which path determine the ORR/OER on the $\mathrm{CuN}_{4}$ co-doped graphene. Scaling relation and surface phase diagram are obtained by calculated Gibbs free energy of intermediates at surface active sites with various adsorption species. The different working potentials are also considered for the studied catalysts, as the overpotential of ORR is also an important indexes of the catalytic activities of the catalyst, we calculated the overpotential for each active site on the structures and determined the minimum overpotential for ORR.
\end{abstract}

\section{Graphic abstract}

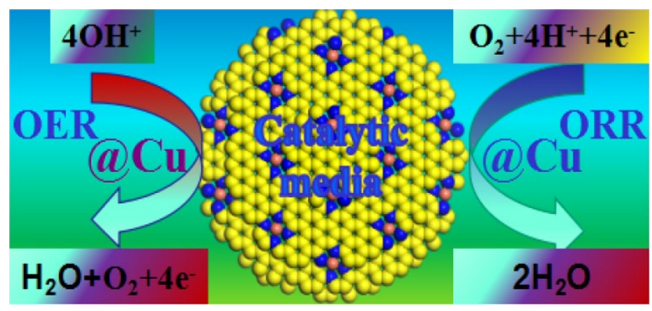

Keywords $\mathrm{CuN}_{4}$-Gra coordinated structure · Oxygen reduction mechanism · Activity barrier · Gibbs energy change . Surface phase diagram

Electronic supplementary material The online version of this article (https://doi.org/10.1007/s42452-020-2009-8) contains supplementary material, which is available to authorized users.

$\triangle$ Yi Xiao, yixiao@tmm.tu-darmstadt.de | Institute of Materials Science, TU Darmstadt, 64287 Darmstadt, Germany. ${ }^{2}$ School of Physics and Optoelectronic Engineering, Yangtze University, Jingzhou 434023, People's Republic of China. 


\section{Introduction}

The metallic and $\mathrm{N}$ doped 2D materials embedded structure such as graphitic [1-3], pyridinic [4-6], and pyrrolic $\mathrm{N}[7,8]$ and metal- $\mathrm{N}$ heterogeneous structures have been investigated to be as promising catalytic substitutes for oxygen reduction reaction (ORR) and initiate a command in an application to fuel cells in recent years $[9,10]$. The metal and $\mathrm{N}$ heteroatoms of embedded structure could tune the charge distribution and change catalytic activity of graphite due to the difference in electronegativity between the contiguous $\mathrm{N}$ and $\mathrm{C}$ atoms. Currently their main usage is focused to as reliable energy storage or energy conversion device applications, $[11,12]$ the main challenges need to be overcome are related to the storage of $\mathrm{O}_{2}$, and energy conversion efficiency. Thanks to the high energy conversion efficiency and storage density of the ORR process for fuel cells, [13] it have been applied massively in portable electronic devices. Metal$\mathrm{N}$ doped graphite catalytic materials have attracted immense attention, due to the high catalytic activity for ORR/OER reactions as power sources for electric vehicles [14]. For example, there are considerable works which reveals metal- $\mathrm{N}$ graphite materials has exhibited a higher ORR activity than non-metallic $\mathrm{N}$-doped graphene; $[15,16]$ Recently, some theoretical investigations have shown that nitrogen-coordinated transition metals (e.g., $\mathrm{Mn}, \mathrm{Fe}$, and $\mathrm{Co}$ ) in graphene exhibit also good ORR catalytic activity $[17,18]$. Bai et al. [19] studied the reaction mechanism for oxygen reduction reaction (ORR) on $\mathrm{P}$-doped graphene through the DFT method, resulting that P-doped graphite could exhibit high electrocatalytic activity, the most favorable reaction pathway is the hydrogenation of $\mathrm{O}_{2}$ molecule to form $\mathrm{OOH}$, then the hydrogenation of $\mathrm{OOH}$ gives $\mathrm{H}_{2} \mathrm{O}$ and atomic $\mathrm{O}$ in ORR. Liu et al. [20] found that Fe/N-doped graphene could create a promising catalytic activity for ORR, and it can be as guidance for catalytic material design. Lu et al. [21] has studied the formation energy for $\mathrm{MnN}_{4}$ embedded in graphene with dispersion-corrected density functional theory study for application in fuel cell devices, it is conducive to the design and improvement of catalyst ORR efficiency. Baran et al. [22] have investigated the ORR on metalloporphyrin combined with graphene based on metal $\mathrm{MN}_{4}$ structures, resulting that there is a sensible scaling relationships between the Gibbs free energies and overpotential of oxygenated species (such as $\mathrm{O}, \mathrm{OH}$ and $\mathrm{OOH}$ ) during the ORR process, [23] it implied a volcano plots within overpotential versus adsorption Gibbs free energy of oxygenated species of ORR activity. The free energy of the ORR intermediates can be calculated by using the procedures proposed by Nørskov et al.
[24] the details about the calculation methods can be found elsewhere $[25,26]$ by calculation barrier energy can determine the most favorable reaction pathway of elementary reaction steps.

In this study we assume that the temperature is constant at $298.15 \mathrm{~K}$ with $\mathrm{pO}_{2}=0.1 \mathrm{bar}$ [27], thus the change in Gibbs free energy caused by the temperature effect is neglected and included only phase state, solvation and hydrogen bonds correction [28]. The scope of this work is to explore the pathway of the reaction mechanism and the thermokinetics of the involved elementary reaction steps for ORR/OER on the $\mathrm{CuN}_{4}$ active site. To further identify the most favorable pathway for ORR was performed to locate transition states (TS) and obtain barrier energy by CI-NEB method. [29, 30] There are two possible reaction pathways for $\mathrm{O}_{2}$. One is $\mathrm{O}_{2}$ can capture one atomic $\mathrm{H}$ to form an $\mathrm{OOH}$ species and another is $\mathrm{O}_{2}$ dissociation. During ORR and OER process, it found that there are several possible elementary reaction steps, such as $\mathrm{OH}$ and $\mathrm{OOH}$ dissociation, atomic $\mathrm{O}$ hydrogenation and $\mathrm{OH}$ diffusion. According to the original plan, we shall describe these reaction pathways in detail by the theory developed by Nørskov et al. [24] It can correctly describe the activation energy and reaction energy of Elementary reaction processes [31]. Moreover, the solvation and phase state effects are considered by a correction to the ORR from free energy in the calculations. It can be reflected in our calculations for the adsorption of intermediates, the DFT results show that the catalytic activity of the $\mathrm{CuN}_{4}$-graphite is comparable to that of $\mathrm{Fe}$ and $\mathrm{Mn}$ graphite embedded structure electrocatalysts catalyst, it demonstrates that the ORR on this class of catalysts can proceed via several reaction pathways with barrier and reaction energy.

\subsection{Computational detail}

All the calculations of geometric and energy are executed within the framework of density functional theory (DFT) method implemented in the VASP code $[32,33]$. The Generalized Gradient Approximation (GGA) with Perdewe Burkee Ernzerhof functional (PBE) is used to describe the exchange correlation potential. A cutoff energy of Plane-Wave basis was sets with an adequate of $400 \mathrm{eV}$ and accurate precision of convergence for the geometry optimization are set to $10^{-4} \mathrm{eV} / \AA ̊$ for energy change, all atomic structures were fully optimized until the forces were smaller than $-0.05 \mathrm{eV} / \AA$. The K-point samplings of Brillouin zone integration was as implemented on a grid of $4 \times 4 \times 1$ MonkhorstePack method for relaxation calculations and transition state (TS) search by conjugate gradient (CG) method is performed, and a $7 \times 7 \times 1$ grid was used for electronic structure computations (showed in Fig. 1d, e), a periodic $(4 \times 4 \times 1)$ supercell of $\mathrm{CN}_{4} \mathrm{Cu}$ coordinated 
Fig. 1 a Geometric structure of $\mathrm{CN}_{4} \mathrm{Cu}$ graphene coordinated structure in a $4 \times 4 \times 1$ supercell. The gray and blue balls represent $\mathrm{C}$ and $\mathrm{N}$ atoms, respectively. b For local areas of supercell with 3 carbon atoms between the nitrogen atoms in the active site, and copper atom lies in the center site. c A schematic diagram of Brillouin zone, $\mathbf{d}$, e band structure and PDOS of $\mathrm{CN}_{4} \mathrm{Cu}$ grapheme coordinate, respectively

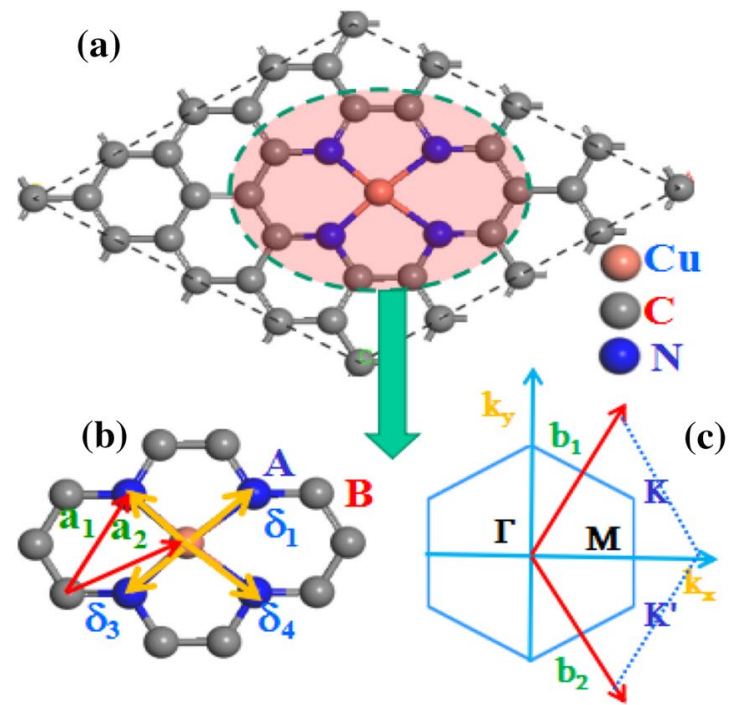

$\begin{array}{cccc}\Gamma & M & K & \Gamma\end{array}$

(c)

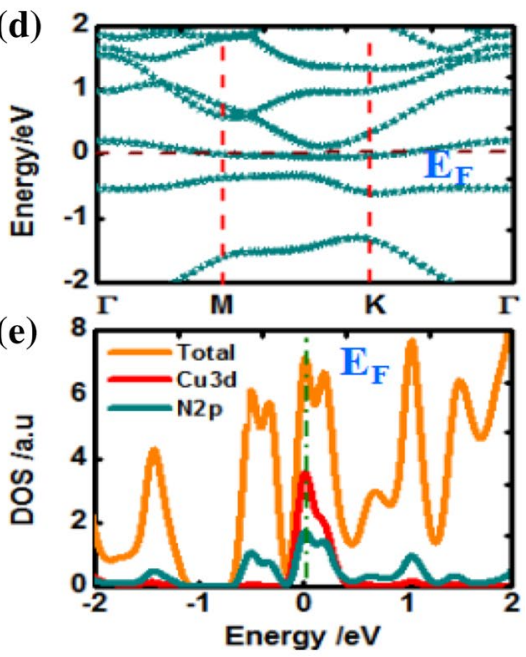

structure graphite were selected for used. The real space thickness in the c direction was set to $15 \AA$ in all the computations in which to ensure there is no interactions within the periodic boundary conditions [34]. The climbingimage nudged elastic band (CI-NEB) method was used to calculate activation energy for each step reaction, there are six images are insert along the favorable path to search for transition states (TS), it employed to locate the saddle points (TS) and reaction path alone the smallest energy barrier choose as the reaction pathway [35, 36]. The Gibbs free energy of the ORR intermediates can be calculated from the procedures proposed by Nørskov et al. For each path, the activation energy ( $\triangle$ Eact) and reaction energies $(\Delta \mathrm{E})$ were calculated by using formulas: $\Delta E \mathrm{Eact}=E_{\mathrm{TS}}-E_{\mathrm{IS}}$ and $\Delta E=E_{\mathrm{FS}}-E_{\mathrm{IS}}$, here IS, TS, and FS correspond to the initial state, transition state, and final state, respectively. The Gibbs free energy $(\Delta G)$ is given by the follow formula: $\Delta \mathrm{G}=\Delta \mathrm{E}+\Delta \mathrm{ZPE}-\mathrm{T} \Delta \mathrm{S}$, it needs correction for $\mathrm{H}$-bonds and phase states of the molecule are executed within the VASPKIT code. Here, $\triangle E$ is the formation energy of intermediates can be obtained from DFT calculations, $\triangle Z P E$ is the correction of zero point energy and entropic $(T \Delta S)$ within $298.15 \mathrm{~K}$, it can be calculated based on the vibrational frequencies $[37,38]$.

\section{Results and discussion}

\subsection{Various ORR involved species}

In order to make a thoughtful study the mechanism of ORR $\left(\mathrm{O}_{2}\right)$ and $\mathrm{OER}(\mathrm{OH})$ in both acidic and alkaline media on $\mathrm{CuN}_{4}$-graphite surface, firstly we need analyze the adsorption energy of various intermediate structure, it involved possible species in ORR/OER mechanism on the catalytic active medium, the possible molecule adsorption configurations of the various species on in reaction mechanism, it includes $\mathrm{O}_{2}, \mathrm{O}, \mathrm{OH}, \mathrm{OOH}$, and $\mathrm{H}_{2} \mathrm{O}$. For the ORR process, the $\mathrm{O}_{2}$ molecule adsorption on the catalyst surface is the most essential step in initiating the entire ORR. Meanwhile, the water molecule adsorption is the most important for an OER process. So a suitable $\mathrm{O}_{2}$ and $\mathrm{H}_{2} \mathrm{O}$ adsorption energy are essential for sufficiently active molecules during the reaction process [39]. The optimized geometry and the calculated Eads for both the most stable and some selected stable mono molecular and co-adsorption configurations are summarized in Fig. 2. It is well known that the physical absorption of $\mathrm{O}_{2}$ and $\mathrm{H}_{2} \mathrm{O}$ are the prerequisite whatever the ORR/OER proceed via the $4 \mathrm{e}$ transfer process, the other intermediates are chemisorption, it involves $\mathrm{O}$, $\mathrm{OH}$ and $\mathrm{OOH}$ and their adsorption energy is significantly greater than that of $\mathrm{H}_{2} \mathrm{O}$ and $\mathrm{O}_{2}$ molecule. So the most stable adsorption configuration of $\mathrm{O}_{2}$ and $\mathrm{H}_{2} \mathrm{O}$ is first determined in my study, the corresponding adsorption energy is calculated by the follow equation:

$\Delta E_{\text {ads }}=E_{\text {adsorbate/Sub }}-E_{\text {Sub }}-E_{\text {adsorbate }}$

It means that the total energy of the adsorbed configurations subtracting the total energy of the substrate $\left(\mathrm{CN}_{4} \mathrm{Cu}\right.$ surface) and $\mathrm{H}_{2} \mathrm{O}$ or $\mathrm{O}_{2}$ molecule. Meanwhile, stable adsorption systems and the corresponding formation energy for all possible ORR step intermediate products are obtained by the follow methods reports [40,41].

The intermediates $(\mathrm{O}, \mathrm{OH}$ and $\mathrm{OOH})$ energetically favorable adsorption configurations are shown in Fig. 2, and the co-adsorption configurations are shown in Figs. 3 and 4. It is found that the $\mathrm{OH}$ prefers to stay at the $\mathrm{Cu}$ top site and $\mathrm{O}$ at the six-member ring or the five-member ring when they co-adsorption, the Eads of the $\mathrm{OH}$ in the co-adsorption 
Fig. 2 Atomic structures of the relaxed for various ORR intermediates a $\mathrm{OOH}, \mathbf{b} \mathrm{O}, \mathbf{c ~ O H}$, and $\mathbf{d} \mathrm{H}_{2} \mathrm{O}$ on $\mathrm{CuN}_{4}$-co-doped graphene. The Eads (eV/mol) and adsorption distance $(\AA)$ for the related species are marked in the figures

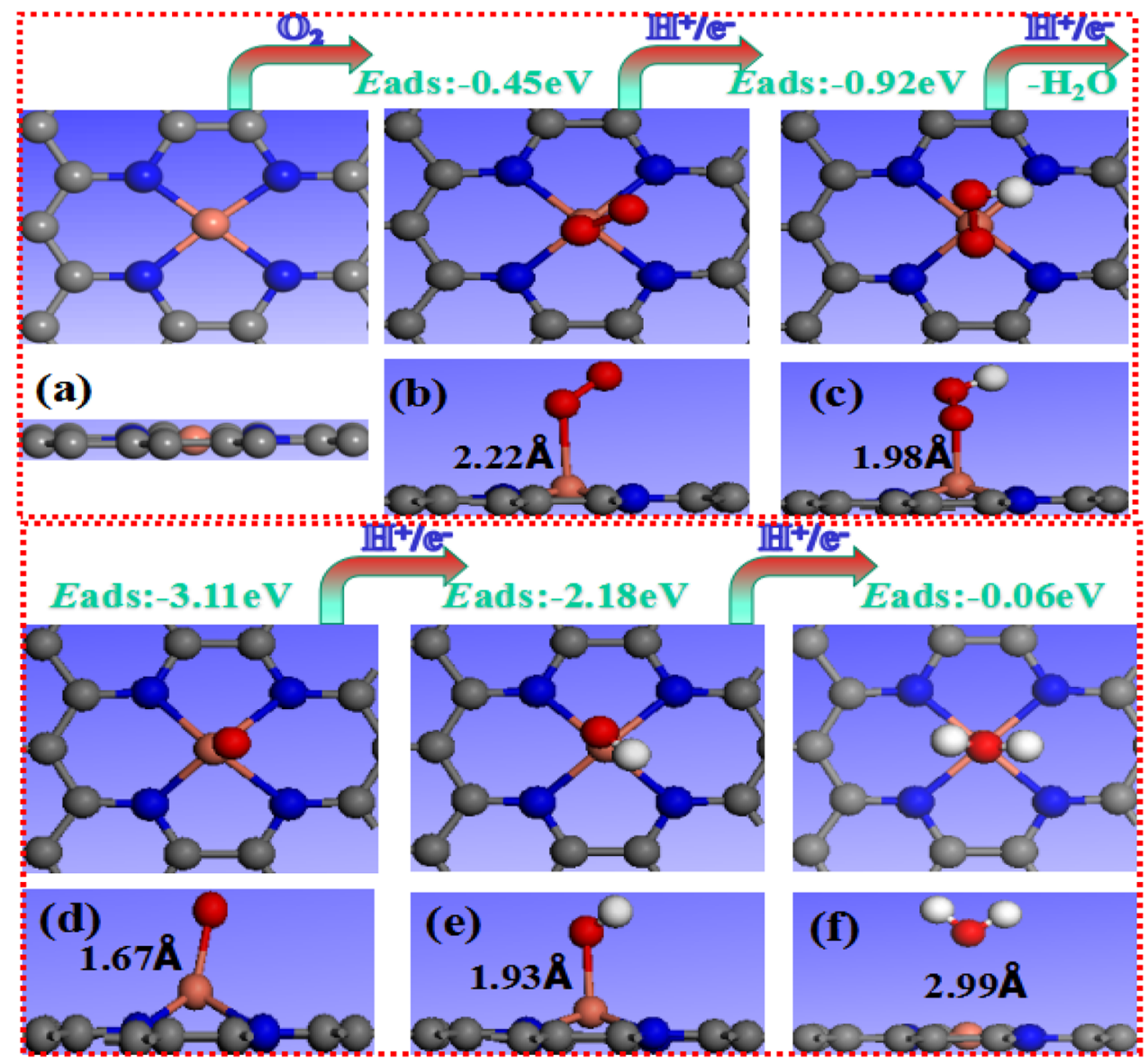

configurations are -2.91 and $-3.64 / \mathrm{eV}$ with $\mathrm{OH}$ and atomic $\mathrm{H}$, respectively. For the $\mathrm{OH}$ and $\mathrm{H}$ co-adsorption two $\mathrm{OH}$ co-adsorption, the Eads's is -4.91 and $-4.28 / \mathrm{eV}$, respectively. These results indicate that a strong interaction exists between these species and the catalytic surface. It should be noted that small adsorption energy of $\mathrm{H}_{2} \mathrm{O}(-0.05 \mathrm{eV})$. The weak interactions indicate that the water can be easily released as the final production of ORR. It different from the calculation method of adsorption energy of neutral molecules $\left(\mathrm{O}_{2}\right.$ or $\left.\mathrm{H}_{2} \mathrm{O}\right)$, the intermediates ${ }^{*} \mathrm{O},{ }^{*} \mathrm{OH}$, and ${ }^{*} \mathrm{OOH}$, must be inferred from the relative to $\mathrm{H}_{2} \mathrm{O}(\mathrm{I})$ and $\mathrm{H}_{2}(\mathrm{~g})$ molecules, they are defined as the following formula from Eqs. (2) to (4):

$$
\begin{aligned}
& \mathrm{GrM}+\mathrm{H}_{2} \mathrm{O}(\mathrm{I}) \leftrightarrow \mathrm{GrM}-\mathrm{O}+\mathrm{H}_{2}(\mathrm{~g}) \\
& \Delta E_{\mathrm{O}}=E_{\mathrm{GrM}-\mathrm{O}}-E_{\mathrm{GrM}}-\left(E_{\mathrm{H}_{2} \mathrm{O}}-E_{\mathrm{H}_{2}}\right) \\
& \mathrm{GrM}+\mathrm{H}_{2} \mathrm{O}(\mathrm{I}) \leftrightarrow \mathrm{GrM}-\mathrm{OH}+1 / 2 \mathrm{H}_{2}(\mathrm{~g}) \\
& \Delta E_{\mathrm{OH}}=E_{\mathrm{GrM}-\mathrm{OH}}-E_{\mathrm{GrM}}-\left(E_{\mathrm{H}_{2} \mathrm{O}}-1 / 2 E_{\mathrm{H}_{2}}\right) \\
& \mathrm{GrM}+2 \mathrm{H}_{2} \mathrm{O}(\mathrm{I}) \leftrightarrow \mathrm{GrM}-\mathrm{OOH}+3 / 2 \mathrm{H}_{2}(\mathrm{~g}) \\
& \Delta E_{\mathrm{OOH}}=E_{\mathrm{GrM}-\mathrm{OH}}-E_{\mathrm{GrM}}-\left(E_{\mathrm{H}_{2} \mathrm{O}}-1 / 2 E_{\mathrm{H}_{2}}\right)
\end{aligned}
$$

Moreover, we set it for four electronic ORR reaction path processes and shown as follows from stage 5 to stage 8 . In the whole $\left(\mathrm{O}_{2}+4 \mathrm{H}^{+}+4 \mathrm{e}^{+} \rightarrow 2 \mathrm{H}_{2} \mathrm{O}\right)$ process contains four stages as follows formulas, and the Gibbs free energy calculation of its corresponding to intermediate reaction as defined by eqn from Eqs. (5) to (8),

$\mathrm{O}_{2}(\mathrm{~g})+\left(\mathrm{H}^{+}+\mathrm{e}^{-}\right)+\mathrm{GrM} \rightarrow \mathrm{GrM}-\mathrm{OOH}$

$\mathrm{GrM}-\mathrm{OOH}+\left(\mathrm{H}^{+}+\mathrm{e}^{-}\right) \rightarrow \mathrm{GrM}-\mathrm{O}+\mathrm{H}_{2} \mathrm{O}$

$\Delta \mathrm{G}_{2}=\Delta \mathrm{G}_{* \mathrm{O}}-\Delta \mathrm{G}_{* \mathrm{OOH}}+\mathrm{eU}$

$\mathrm{GrM}-\mathrm{O}+\left(\mathrm{H}^{+}+\mathrm{e}^{-}\right) \rightarrow \mathrm{GrM}-\mathrm{OH}$

$\Delta \mathrm{G}_{3}=\Delta \mathrm{G}_{* \mathrm{O}}-\left(\Delta \mathrm{G}_{* \mathrm{OH}}-\mathrm{eU}\right)$

$\mathrm{GrM}-\mathrm{OH}+\left(\mathrm{H}^{+}+\mathrm{e}^{-}\right) \rightarrow \mathrm{GrM}-\mathrm{H}_{2} \mathrm{O}$

$\Delta \mathrm{G}_{4}=\mathrm{eU}-\Delta \mathrm{G}_{* \mathrm{OH}}$

Furthermore, there are some small additional effect on the ORR adsorbates, such as solvation have estimated as 0.3 / 
Fig. 3 Summary of adsorption intermidates species its dissociation energies and reaction energies of adsorbates on the on $\mathrm{CuN}_{4}$-graphfite surface
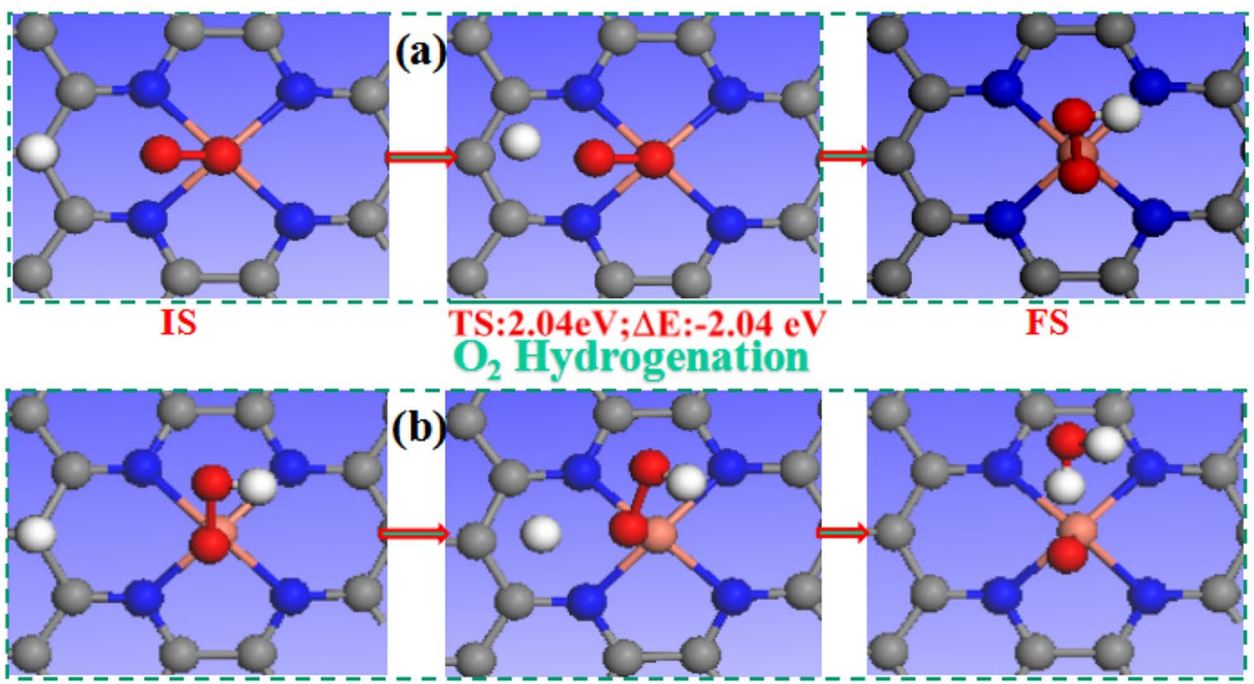

IS

TS:0.20eV; $\Delta \mathrm{E}:-1.46 \mathrm{eV}$ FS

$\mathrm{OOH}$ into $\mathrm{H}_{2} \mathrm{O}$ and atomic $\mathrm{O}$

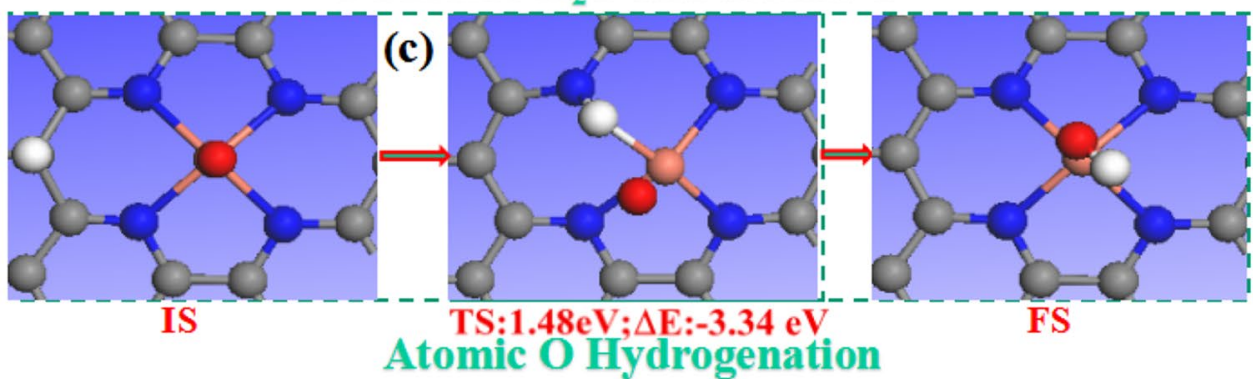

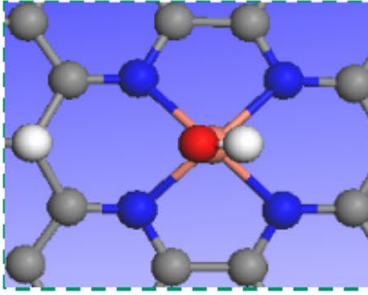

IS

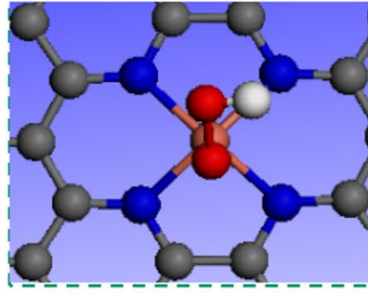

IS (d)

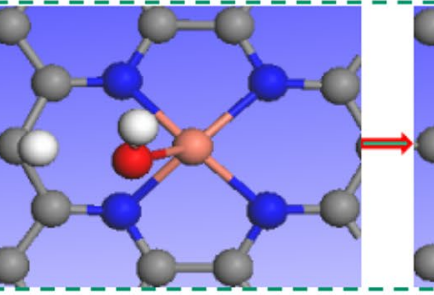

TS:0.20eV; $\Delta \mathrm{E}:-1.46 \mathrm{eV}$ $\mathrm{OH}$ Hydrogenation

(e)

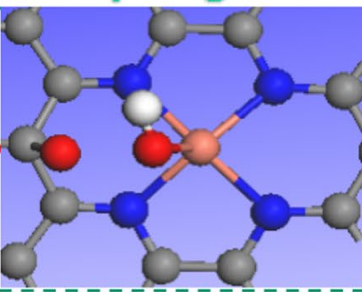

TS:1.06eV; $\Delta \mathrm{E}: 0.94 \mathrm{eV}$

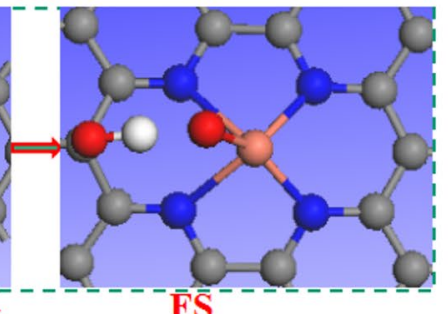

$\overline{\mathbf{F}} \overrightarrow{\mathrm{S}}$

OOH Dissociation

$\mathrm{eV}$, phases states have estimated as $0.45 / \mathrm{eV}$ and hydrogen bonds in the liquid phase state will be stabilized by $0.30 / \mathrm{eV}$ when solvated transfer solution medium, so Gibbs free energy needs correction. In this work, we set to $\Delta G_{\mathrm{O}}=\Delta E_{\mathrm{O}}-0.30 ; \Delta G_{\mathrm{OH}}=\Delta E_{\mathrm{OH}}+0.35 ; \Delta G_{\mathrm{OOH}}=\Delta E_{\mathrm{OOH}}+0.40$ to adsorbed species as reported in Refs. $[42,43]$. The term
$\Delta G_{W}$ is equal to $-2.96 \mathrm{eV}$ for a $\mathrm{H}_{2} \mathrm{O}$ molecules form. The total Gibbs free energy $\left(\Delta \mathrm{G}_{1}+\Delta \mathrm{G}_{2}+\Delta \mathrm{G}_{3}+\Delta \mathrm{G}_{4}\right)$ of full reaction is obtained from the reaction of $\mathrm{O}_{2}+2 \mathrm{H}_{2} \rightarrow 2 \mathrm{H}_{2} \mathrm{O}$, which is $-4.92 \mathrm{eV}$ at temperature of $298.15 \mathrm{~K}$ with pressure of 0.035 bar. 
Fig. 4 Summary of adsorption intermidates species its dissociation energies and reaction energies of adsorbates on the on $\mathrm{CuN}_{4}$-graphfite surface

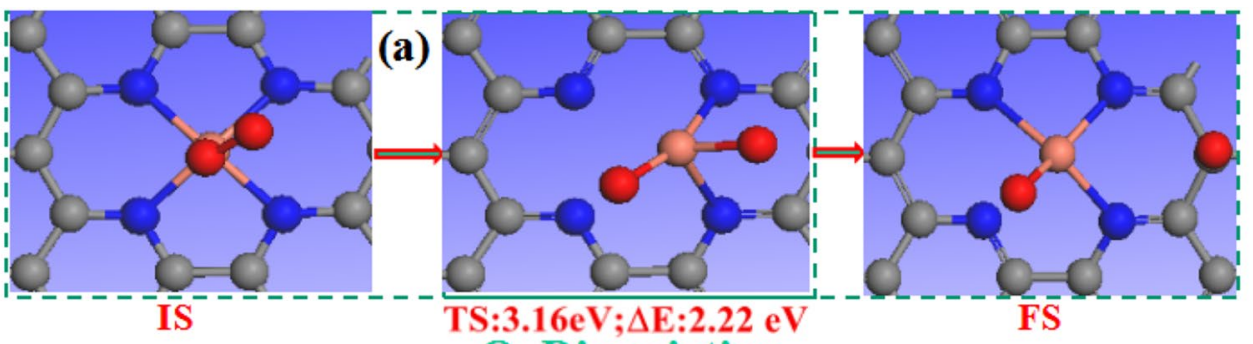

$\mathrm{O}_{2}$ Dissociation

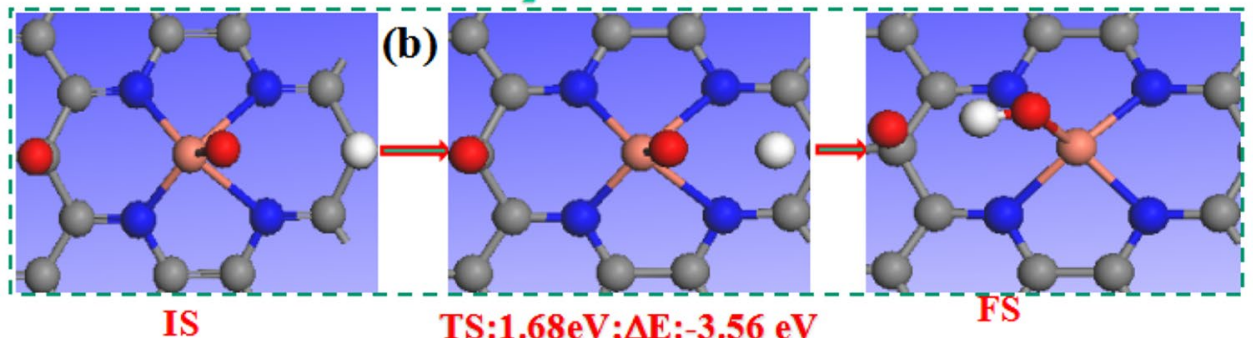

IS

TS:1.68eV; $\Delta \mathrm{E}:-3.56 \mathrm{eV}$

Atomic $\mathrm{O}$ Hydrogenation

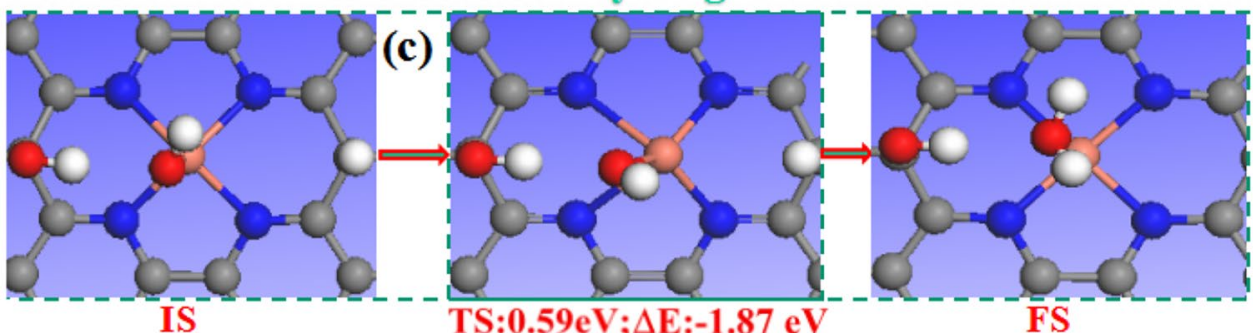

$20 H$ Disproportionation

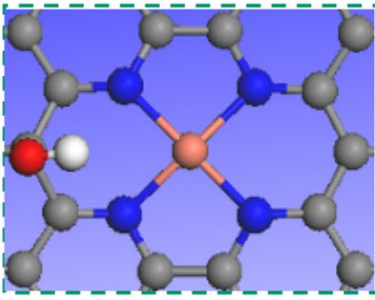

IS

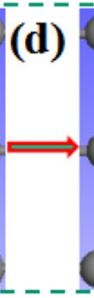

TS:0.69eV; $\Delta \mathrm{E}:-0.36 \mathrm{eV}$ OH Diffusion
It is found from Fig. 2 that the central $\mathrm{Cu}$ atom serves as the catalytic activity and the most stable adsorption sites for all ORR reaction intermediate species, which agree well with some relate previous work [44]. The first stage, $\mathrm{O}_{2}$ tends to adsorbate on the top of the $\mathrm{Cu}$ atom and formed a Cu-O bond distance of $2.22 \AA$ with adsorption energy of $-0.45 / \mathrm{eV}$, and $\mathrm{H}_{2} \mathrm{O}$ absorbed on the top of $\mathrm{Cu}$ atom with a smaller adsorption energy $(0.055 \mathrm{eV})$ than $\mathrm{O}_{2}$ molecule as show in Fig. 2a, e, respectively. For the electronic structure of bare surface (see Fig. 1d, e), the extra electrons compel the $2 p$ states of $\mathrm{N}$ to $\mathrm{Cu} 3 d$ states which across to the Fermi energy and activating the adjacent carbon atoms, eventually resulting in the obvious enhanced adsorption properties of adsorbed species. In addition to the hybridization of N2p* states with the C $2 p$ state around the Fermi energy, the hybridization of $2 p$ states of $\mathrm{C}$ and $\mathrm{N}$ is also observed. This speculation is corroborated by the large binding energy of intermediates, see from Fig. 2, about $-2.18 \mathrm{eV}$ for ${ }^{*} \mathrm{OH},-3.11 / \mathrm{eV}$ for ${ }^{*} \mathrm{O}$, and for $-0.92 / \mathrm{eV}$ for ${ }^{*} \mathrm{OOH}$, respectively.

\subsection{ORR mechanism of $\mathrm{O}_{2}$}

The ORR process of $\mathrm{O}_{2}$ may occur via two mechanisms. One is direct dissociation into two atomic $\mathrm{O}$ and another is associative to form $\mathrm{OOH}$ with one atomic $\mathrm{H}$, all the two mechanisms make the adsorbed $\mathrm{O}_{2}$ molecule sequentially hydrogenates into the final product $\mathrm{H}_{2} \mathrm{O}$. In the associative pathway, a $\mathrm{O}_{2}$ hydrogenation occurs to form $\mathrm{OOH}$ species and then it can be either hydrogenated to form $\mathrm{H}_{2} \mathrm{O}$ and 
one $\mathrm{O}$ atomic, and then the atomic $\mathrm{O}$ sequentially hydrogenates into the final product $\mathrm{H}_{2} \mathrm{O}$ with two atomic $\mathrm{H}$. In addition, the overall possible reaction pathways are shown in Figure 1S (see from supporting information), where the individual possible reaction step of the dissociative pathways are shown. The relative reaction energy $(\Delta \mathrm{E})$ and reaction barrier energy (Eact) profiles of all reaction steps for the $\mathrm{O}_{2}$ molecule with atomic $\mathrm{H}$ ORR process are presented in Fig. 3a. As a rule, the total energy of the $\mathrm{O}_{2}$ adsorbed process on $\mathrm{CuN}_{4}$-graphene surface is used as the critical state, the adsorption energy of the states during the reduction steps is $-0.45 / \mathrm{eV}$ see in Fig. 2 . The detailed data on all potential reaction step reaction energy and barrier energy are summarized in Fig. 3 in the supporting information. According to the calculated reaction barriers, the reaction pathway (as the red line in Fig. 8) is the most favorable pathway (reaction mechanism I) throughout the entire ORR. According to the reaction stages presented above, there are four possible stage for the ORR process on the $\mathrm{CuN}_{4}$-gra surface is first stage with the highest reaction barrier of 2.04/eV, it corresponding to the hydrogenation process of the $\mathrm{O}_{2}$ molecule with one atomic $\mathrm{H}$ to form the $\mathrm{OOH}$ species. Meanwhile, the rate-limiting stage of $\mathrm{O}_{2}$ dissociation mechanism process with a high reaction barrier energy of $3.16 / \mathrm{eV}$, corresponding to the $\mathrm{O}_{2}$ change into two atomic $\mathrm{O}$.

We carried out density functional theory (DFT) calculations of the active sites and the overall possible reaction pathways are illustrated in Fig. 8, where the individual microsteps of the dissociative pathway and associative pathway. In a word, it is seen from all the possible reaction pathways that for $\mathrm{O}_{2}$ dissociation, the favorable pathway is the process a $\mathrm{O}_{2} \rightarrow 2^{*} \mathrm{O} \rightarrow 2{ }^{*} \mathrm{OH} \rightarrow{ }^{*} \mathrm{O}$ and $\mathrm{H}_{2} \mathrm{O} \rightarrow{ }^{*} \mathrm{O} \rightarrow{ }^{*} \mathrm{OH} \rightarrow \mathrm{H}_{2} \mathrm{O}$ form with the rate determining step of $\mathrm{O}_{2}$ dissociation (barrier activity $3.16 / \mathrm{eV}$ ). It need note that ${ }^{*} \mathrm{OH}+{ }^{*} \mathrm{OH} \rightarrow{ }^{*} \mathrm{O}+\mathrm{H}_{2} \mathrm{O}$ with a barrier energy of $0.62 \mathrm{eV}$ and ${ }^{*} \mathrm{OH}+{ }^{*} \mathrm{OH}+\mathrm{H}^{+} \rightarrow{ }^{*} \mathrm{OH}+\mathrm{H}_{2} \mathrm{O}$ with a similar barrier energy $(0.59 / \mathrm{eV})$. It indicates that they are competitive pathways. Nonetheless, we also noted that the second atomic * $\mathrm{O}$ hydrogenation to form $\mathrm{OH}$ have the smallest energy barriers $(0.26)$. On the other hand, the $\mathrm{O}_{2}$ hydrogenation is the process a $\mathrm{O}_{2}$ hydrogenation $\rightarrow{ }^{*} \mathrm{OOH}$ dissociation $\rightarrow$ atomic ${ }^{*} \mathrm{O}$ and $\mathrm{OH} \rightarrow{ }^{*} \mathrm{O}$ hydrogenation $\rightarrow{ }^{*} \mathrm{OH}$ hydrogenation $\rightarrow \mathrm{H}_{2} \mathrm{O}$ form with the rate-determining step of $\mathrm{O}_{2}$ hydrogenation (barrier energy $1.98 \mathrm{eV}$ ) preferred due to a smaller energy barrier than $\mathrm{O}_{2}$ dissociation $(3.16 \mathrm{eV})$. The formed $\mathrm{OH}$ species is stable on the $\mathrm{Cu}$ site, $\mathrm{H}$ atom would diffuse from the five ring site and form $\mathrm{OH}$ with a 1.48 barrier energy and high exothermic reaction energy $(-3.34 / \mathrm{eV})$. For the $\mathrm{OOH}$ dissociation, producing an atomic $\mathrm{O}$ adsorbed on $\mathrm{Cu}$ with a exothermic reaction energy of 0.94/eV (See in Fig. 3e). The formed OH diffuses easily from the five-member ring to the $\mathrm{Cu}$ top site of the six-member ring with a reaction barrier of $0.69 / \mathrm{eV}$ and a small exothermic reaction energy of -0.36 , as presented in Fig. $4 \mathrm{~d}$.

The free energy diagram for the complete $\mathrm{O}_{2}$ reduction at different potentials as shown in Fig. 5 , direct dissociation of $\mathrm{O}_{2}$ molecule into two atomic $\mathrm{O}$ atoms, it requires
Fig. 5 The possible ORR and OER pathways on single copper doped graphite, the free energy profiles for the ORR pathway $(\mathbf{a}, \mathbf{b})$ and the OER pathway $(\mathbf{c}, \mathbf{d})$ on $\mathrm{CuN}_{4}$-graphite surface for the complete $\mathrm{O}_{2}$ reduction/oxidation at different potentials
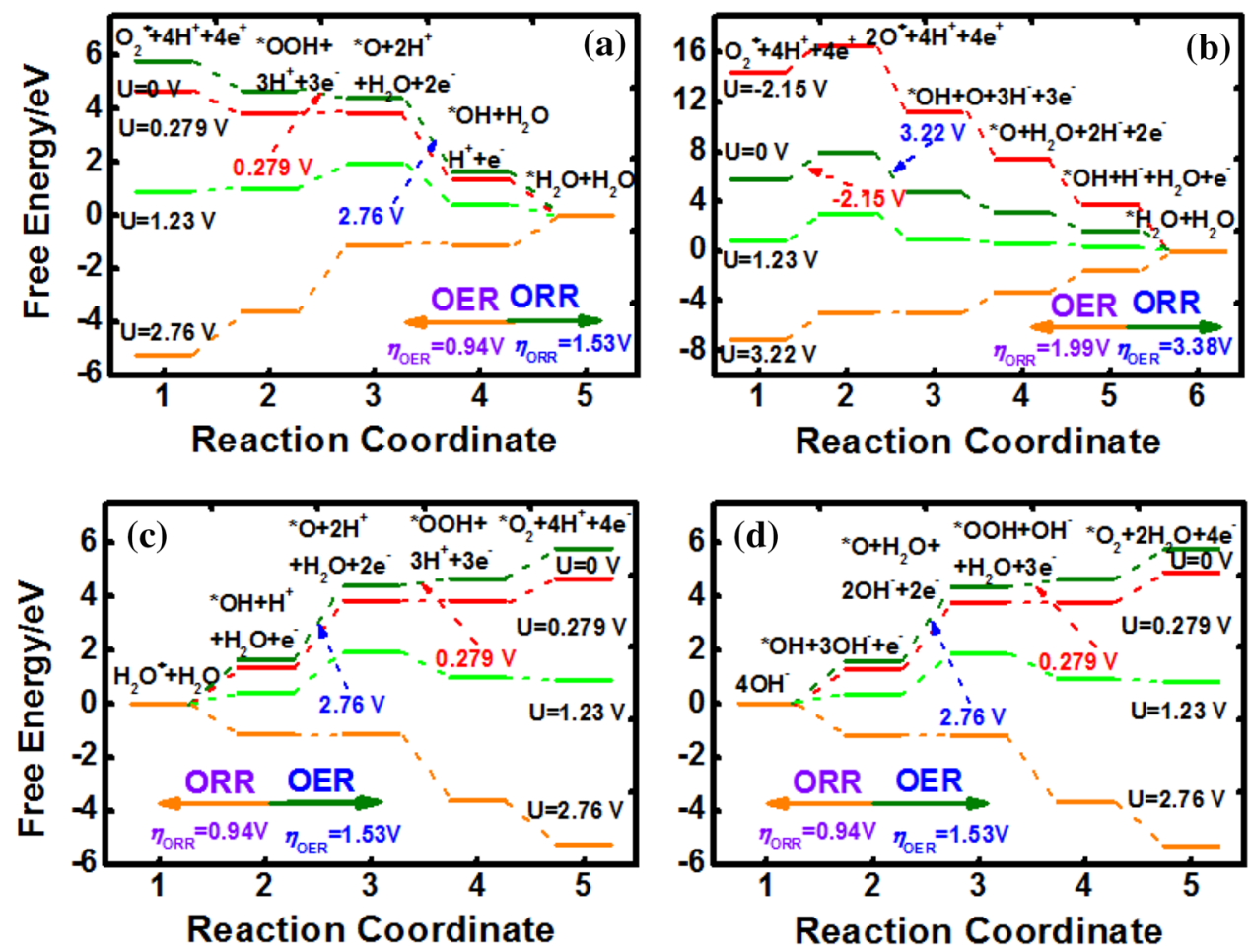

SN Applied Sciences A SPRINGER NatURE journal 
an high energy barrier of $3.16 \mathrm{eV}$, then one atomic on top $\mathrm{Cu}$ hydrogenates with one $\mathrm{H}$ atomic to form ${ }^{*} \mathrm{O}$ and ${ }^{*} \mathrm{OH}$ co-absorption system, and then with another $\mathrm{H}$ atom spontaneous form two ${ }^{*} \mathrm{OH}$, one located on top of $\mathrm{Cu}$ and another was situated above one carbon atom of the six member ring. The rate limiting stage is the $\mathrm{O}_{2}$ dissociation with the reaction barrier of $3.16 \mathrm{eV}$, the hydrogenation of the atomic $\mathrm{O}$ on top of $\mathrm{Cu}$ with first atomic $\mathrm{H}$ to form $\mathrm{OH}$, and then the second $\mathrm{H}$ would diffuse to the $\mathrm{O}$ atom to form $\mathrm{O}+\mathrm{H}_{2} \mathrm{O}$ binding to the $\mathrm{Cu}$, for the other $\mathrm{O}$ atom hydrogenated form $\mathrm{OH}$ with a $0.05 \mathrm{eV}$ energy barrier to the top carbon atom of the six member ring, a high exothermic reaction energy $(-3.01 / \mathrm{eV})$. Subsequently, the $\mathrm{OH}$ species adsorbed on the $\mathrm{Cu}$ to $\mathrm{H}_{2} \mathrm{O}$ form with a $\mathrm{H}$ atom adsorbed on $\mathrm{Cu}$. The $\mathrm{OOH}$ species dissociates with a negligible barrier $(1.06 / \mathrm{eV})$ and high exothermic reaction energy $(0.94 / \mathrm{eV}$ ) (see in Fig. 3e). Moreover, the second $\mathrm{OH}$ diffuses easily from the five-member ring to the Cu top site with a diffusion barrier of $0.69 / \mathrm{eV}$, and a small exothermic reaction energy of $-0.36 / \mathrm{eV}$ as presented in Fig. $4 \mathrm{~d}$. As ${ }^{*} \mathrm{O}+{ }^{*} \mathrm{OH}+{ }^{*} \mathrm{H}$ spontaneously transforms into two $\mathrm{OH}$ radicals and transform into $\mathrm{O}$ and $\mathrm{H}_{2} \mathrm{O}$ with the reaction barrier of $0.59 \mathrm{eV}$. Here, the transition states (TS) are marked by the color dashed rectangular box, the corresponding reaction barrier $\left(\Delta \mathrm{E}_{\mathrm{TS}}\right)$ and reaction energy $(\Delta \mathrm{E})$ by calculated the change energy between products and reactants) are also presented below the TS. The hydrogenation process of ${ }^{*} \mathrm{OH}$ and ${ }^{*} \mathrm{O}$ with one atomic $\mathrm{H}$ may have two different pathways. The first is defined as ${ }^{*} \mathrm{OH}+{ }^{*} \mathrm{O}+\mathrm{H} \rightarrow 2^{*} \mathrm{OH}$ and ${ }^{*} \mathrm{OH}+{ }^{*} \mathrm{O}+\mathrm{H} \rightarrow{ }^{*} \mathrm{O}+\mathrm{H}_{2} \mathrm{O}$. For the first step, $2{ }^{*} \mathrm{OH}$ desorbing from the surface occurs rather efficiently with an activation barrier of less than zero eV, it can not be directly formed ${ }^{*} \mathrm{O}$ and $\mathrm{H}_{2} \mathrm{O}$ whereas it has a high activation barrier $(0.62 / \mathrm{eV})$ and high reaction energy $(0.55 \mathrm{eV}) .2 * \mathrm{OH}$ take one atomic $\mathrm{H}$ to form $\mathrm{O}$ and $\mathrm{H}_{2} \mathrm{O}$, and then the ${ }^{*} \mathrm{O}$ takes $\mathrm{H}$ from another $\mathrm{OH}$ on top $\mathrm{Cu}$, and finally forms the final product $\mathrm{H}_{2} \mathrm{O}$. The $\mathrm{H}_{2} \mathrm{O}$ molecule formed shows small adsorption energy $(-0.055 / \mathrm{eV})$ on top $\mathrm{Cu}$ atom with a distance of $2.99 \AA$, indicating that it easy desorption from the surface. This is an exothermic process with reaction energy of $-3.34 / \mathrm{eV}$ and an activation barrier of $1.48 / \mathrm{eV}$ sees in Fig. 3c. Then, it follows the $\mathrm{OH}+\mathrm{H} \rightarrow \mathrm{H}_{2} \mathrm{O}$ resulting in the final product $\mathrm{H}_{2} \mathrm{O}$ with reaction energy of $-2.26 / \mathrm{eV}$ and a barrier energy of $0.21 / \mathrm{eV}$.

\subsection{Thermodynamics analysis}

To gain further explore of the ORR/OER process at an atomic level. First we convert free energy into Gibbs free energy by correcting, such as solvation correction, hydrogen bonds, phase state and so on. It can be observed in Fig. 6, it showed a constant separation catalytic activity of $0.2 / \mathrm{eV}$ between the energy levels of ${ }^{*} \mathrm{O}$ and ${ }^{*} \mathrm{OOH}$, while that of much more large-scale separation activity site of about $1 \mathrm{eV}$ between ${ }^{*} \mathrm{OH}$ and ${ }^{*} \mathrm{OOH}$, it is consistent with that of previous analyses which concluded that the energy levels of ${ }^{*} \mathrm{OH}$ and ${ }^{*} \mathrm{OOH}$, there have a constant separation of $0.2-3.2 / \mathrm{eV}$ on a wide range of catalytic surface. This constant separation has been attributed to the similarities between ${ }^{*} \mathrm{O}$ and ${ }^{*} \mathrm{OOH}$ with the surface. It is obvious from Fig. $7 b$ (surface phase diagram) that the reduction of $\mathrm{OH}$ into $\mathrm{H}_{2} \mathrm{O}$ is the most occurred step which the potentials higher than $0.82 / \mathrm{V}$, indicating that the protonation of $\mathrm{OH}$ into $\mathrm{H}_{2} \mathrm{O}$ is more easily along the whole reaction
Fig. 6 Volcano plots for a OER and $\mathbf{b}$ ORR on different sites of $\mathrm{CuN}_{4}$-graphene surface, and volcano plots of overpotential $\eta$ versus the difference of binding energy of $\mathrm{C} * \mathrm{O}$ versus ${ }^{*} \mathrm{OH}$ and $\mathbf{d}{ }^{*} \mathrm{OOH}$ versus ${ }^{*} \mathrm{O}$, respectively

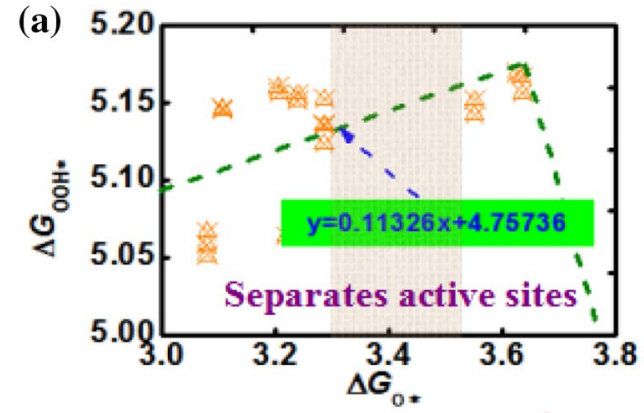

(c)

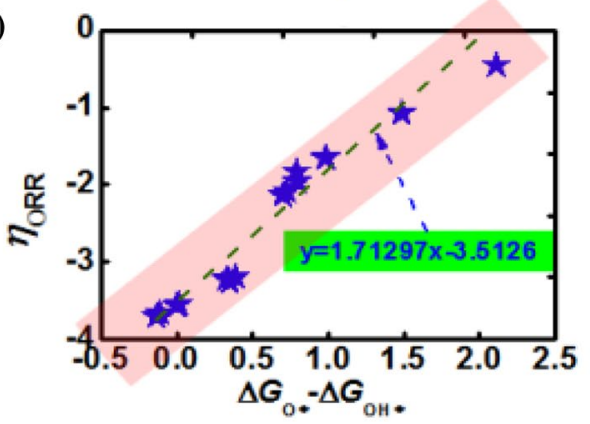

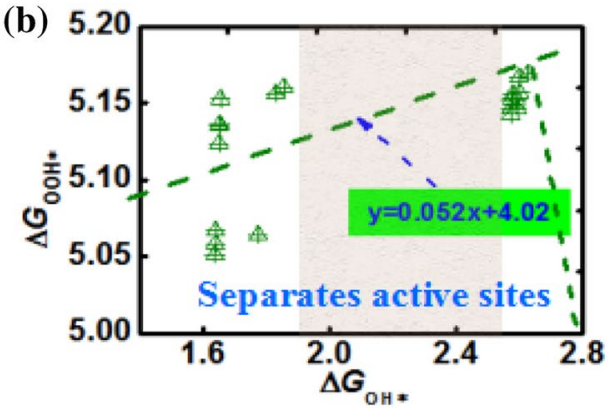

(d)

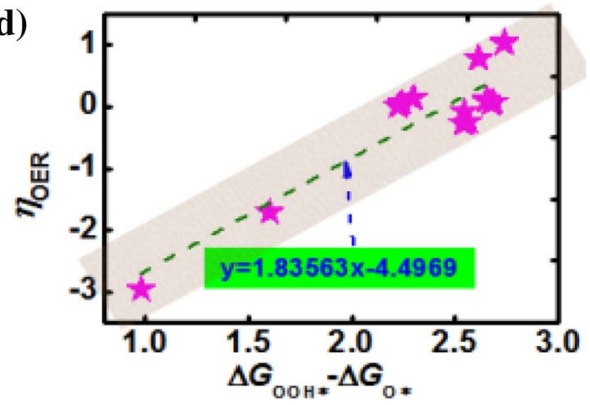


Fig. 7 a Scaling relations surface phase diagram between the formation energies of intermediates for ORR. b Free energy phase diagram in different intermediates (a)

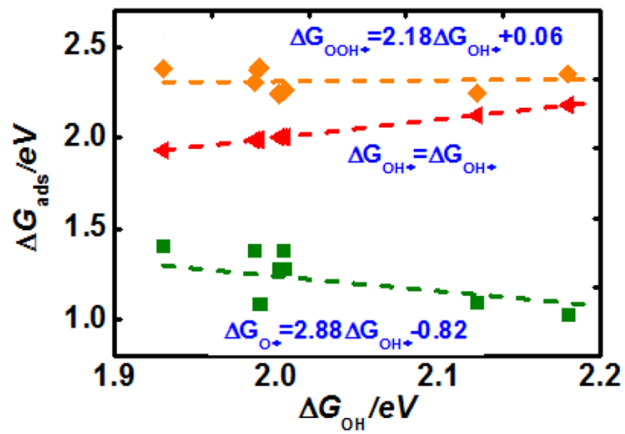

(b)

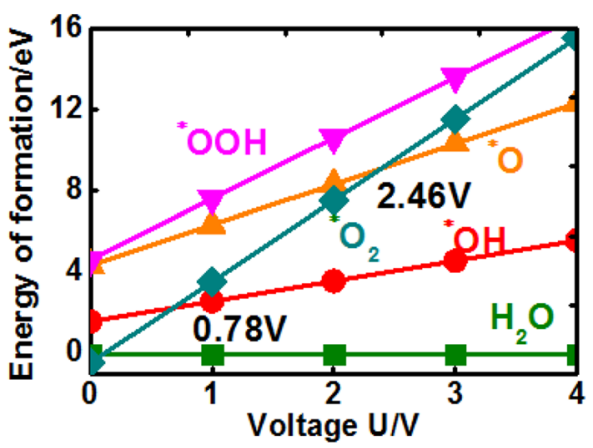

Fig. 8 The different reaction pathway for ORR on $\mathrm{CuN}_{4} \mathrm{CO}$ doped graphene, corresponding activation energy and reaction energies are marked

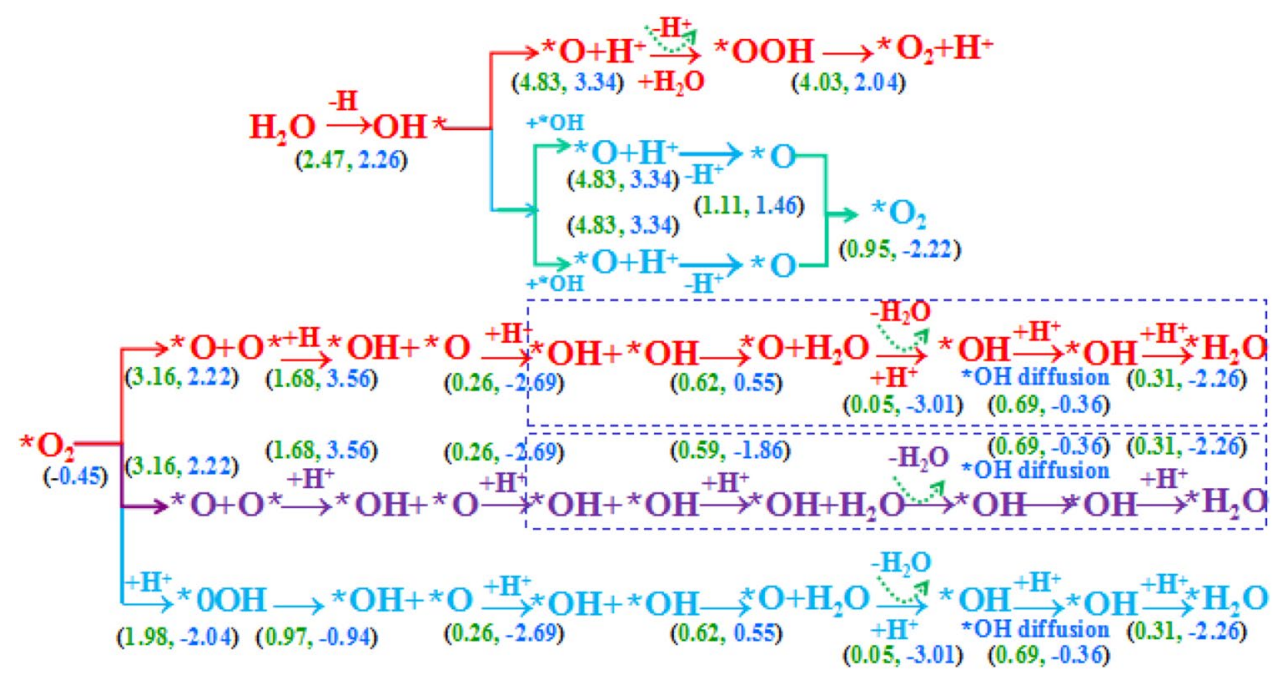

pathway. The reduction of $\mathrm{O}_{2}$ into two atomic *O becomes, the Gibbs energy results show that the ORR proceeds along the energy profiles of the pathway by producing the ${ }^{*} \mathrm{OOH}$ and ${ }^{*} \mathrm{O}$ and ${ }^{*} \mathrm{OH}$ as the main intermediates on $\mathrm{CuN}_{4}$-co-doped graphene. The towards the ORR mechanism of the process has been explored to the interaction between the intermediates and shows a high catalytic activity. As the overpotential of ORR/OER by free energy correction is a crucial index of the catalytic activities of a catalyst materials [44], we calculated the overpotential of all possible active sites and determined the corresponding overpotential for ORR/OER pathways. An ideal catalyst for ORR ( $n_{\mathrm{ORR}}=1.23-\mathrm{U}_{\mathrm{ORR}}$ ) need under the equilibrium potential (1.23/eV) with a smaller overpotential. Meanwhile, an ideal catalyst for OER ( $\eta_{O E R}=U_{O E R}-1.23$ ) need above the equilibrium potential $(1.23 / \mathrm{eV})$ with a smaller overpotential. However, the overpotential unreliable to obtain directly because the free energy of the intermediates are needed to correlate, the lower overpotential indicates the better catalyst. Figure $6 c$, $d$ presents a similar to linear plots, that means the overpotential versus descriptors for various active sites on $\mathrm{CuN}_{4}$-graphite surfaces. Note that the catalytic surface gives the best ORR performance based on the estimate of the volcano plot (Fig. 6a, b). Indicating that the $\mathrm{CuN}_{4}$-graphite catalyst could outperform its graphite materials with transition metal.

As showed in Fig. 7a, we presented the scaling relations between the Gibbs energy of the ORR intermediates, as a function of $\Delta \mathrm{G}_{\mathrm{OH}}$, and Fig. 7b presented the potential dependent surface phase diagram at T $=298 \mathrm{~K}$ and $\mathrm{pO}_{2}=0.1$ bar, corresponding to electron transfer steps $(0.79,2.34 \mathrm{~V})$ is marked by circles, the Gibbs free energy between the voltage of the ORR intermediates. In Fig. 7, we observe a gap with about $-0.11 \sim 2.11 \mathrm{eV}$ in the ${ }^{*} \mathrm{O}$ and ${ }^{*} \mathrm{OH}$ Gibbs free energy and $0.98-2.74 / \mathrm{eV}$ in the ${ }^{*} \mathrm{O}$ and ${ }^{*} \mathrm{OOH}$ Gibbs free energy. As a guide to the eye, we marked a dotted area between 2.26 and $2.93 / \mathrm{eV}$ in the $\mathrm{x}$-axis of Fig. 7a which includes the gaps in the 3 lines. This area strictly separates active sites in each active site. Meanwhile, we sloped the lines ${ }^{*} \mathrm{O}$ versus ${ }^{*} \mathrm{OH}$ (purple) and ${ }^{*} \mathrm{OOH}$ versus ${ }^{*} \mathrm{OH}$ (orange) see in Fig. 7a, the value expected from the scaling relationships analysis and been recognized for work for $\mathrm{Cu}$ with oxides. These equations were also used as input to construct the volcano plot. We note that both the scaling relations are the same the results obtained for free energy analysis. This similarity is expected since the 
linear scaling relations are determined by the Gibbs free energy of binding, the intercept of these relations appears to be determined by the absorption strength of intermediates. All intermediates have only at top binding available, resulting in similar scaling relations. Nevertheless, graphite materials are probably more stable in acidic environments has great importance properties. Moreover, the fact that experimentally the active sites are created in the interstices between graphite layers in porous materials could, in principle improve the ORR/OER activities. [45]

On the basis of abundant results, this work fully summarizes and analyzes the ORR/OER process of $\mathrm{CuN}_{4}-\mathrm{Gra}$ surface from Fig. 8. For the $\mathrm{O}_{2}$ dissociation pathway, the favorable pathway is the process an $\mathrm{O}_{2} \rightarrow{ }^{*} \mathrm{O}$ with the rate determining step of $\mathrm{OH}$ dissociation (barrier activity $3.16 \mathrm{eV}$ ). While the $\mathrm{O}$ hydrogenation of $\mathrm{O}_{2}$ pathway is $\mathrm{OOH}$ form $\rightarrow$ transformation into ${ }^{*} \mathrm{O}$ and $\mathrm{H}_{2} \mathrm{O} \rightarrow{ }^{*} \mathrm{O}$ formation within $\mathrm{H}^{+} \rightarrow$ generate $\mathrm{OH}$ and $\mathrm{OH}$ with the last $\mathrm{H}$ with the $\mathrm{H}_{2} \mathrm{O}$ form, the rate-determining step of $\mathrm{OOH}$ form (the energy barrier of diffusion is $1.98 \mathrm{eV}$ ). However, the formation of $\mathrm{OOH}$ and $\mathrm{H}_{2} \mathrm{O}$ is a spontaneous process for $\mathrm{ORR}$ with negative reactions energy, suggesting that $\mathrm{OOH}$ hydrogenation is more easily than $\mathrm{OOH}$ dissociation (barrier energy $4.03 \mathrm{eV}$ ). The hydrogenation of $\mathrm{OH}$ and atomic ${ }^{*} \mathrm{O}$ with a barrier of $0.31 \mathrm{eV}$ and $0.05 \mathrm{eV}$, respectively. See from Fig. 8, the reaction pathway of $\mathrm{H}_{2} \mathrm{O}$ split, there are two pathways of reaction mechanism, the favorable pathway is the process a $\mathrm{H}_{2} \mathrm{O}$ dissociation $\rightarrow \mathrm{OH}$ dissociation $\rightarrow{ }^{*} \mathrm{OOH}$ formation of atomic ${ }^{*} \mathrm{O}$ with a $\mathrm{H}_{2} \mathrm{O}$ molecule $\rightarrow \mathrm{OOH}$ dissociation into $\mathrm{O}_{2}$ and $\mathrm{H}$ with the rate-determining step of $\mathrm{OH}$ dissociation (energy barrier $4.83 \mathrm{eV}$ ) (see Figure S3). Meanwhile, the favorable pathway is $2 \mathrm{H}_{2} \mathrm{O}$ split into $2 \mathrm{OH}$ and then dissociation to two atomic ${ }^{*} \mathrm{O}$. Finally the two atomic ${ }^{*} \mathrm{O}$ transform into $\mathrm{O}_{2}$ with a energy barrier of $0.95 \mathrm{eV}$ indicating that the $\mathrm{O}_{2}$ hydrogenation is much easier than $\mathrm{O}_{2}$ dissociation and very difficult to spite for water and $\mathrm{OH}$ of OER process of $\mathrm{CuN}_{4}$-graphite surface. Atomic $\mathrm{O}$ is the main intermediates species on the catalyst surface not only but also for OER and ORR process.

\section{Conclusions}

Theoretical calculations revealed that the $\mathrm{CuN}_{4}$ co-doped graphene, it would improve the catalytic activity for the ORR process. This coordination structure has delivered a superior performance compared to conventional metal for catalyzing ORR in fuel cells. First, we calculated the adsorption energy of ORR intermediates, and then calculated reaction energy and barrier energy by using climbing image nudged elastic band (Cl-NEB) method to search transition state of all of the ORR elementary reaction steps, indicating that the $\mathrm{CuN}_{4}$ co-doped graphene as efficient catalyst for ORR The intermediate molecules are always chemisorption at the top of $\mathrm{Cu}$ site on the $\mathrm{CuN}_{4}$ co-doped graphene, it implies that the $\mathrm{N}$-chelated transition metal with carbon plays an important role in the ORR/OER process, the transition metal is the active center for all the possible elementary steps of the ORR. The most favorable pathway is the $\mathrm{O}_{2}$ hydrogenation to $\mathrm{OOH}$ form. $\mathrm{OOH}$ from the calculation of barrier energy for all elementary reaction steps, the hydrogenation of $\mathrm{O}_{2}$ is more easily than $\mathrm{O}_{2}$ dissociation pathways. According to the scaling relations between the Gibbs free energy and the separation activated site gap value expected from the scalingrelationships, the free energy of oxygenated intermediates $\left({ }^{*} \mathrm{OOH},{ }^{*} \mathrm{O}\right.$, and $\left.{ }^{*} \mathrm{OH},\right)$ in ORR approximately linearly scale with each other, it can analysis and known how to work for metals and oxides of the ORR adsorbates and also has great influence on reaction pathways due to the different active sites. Indicating that the $\mathrm{O}_{2}$ hydrogenation is much easier than $\mathrm{O}_{2}$ dissociation. Therefore, our study revealed that the single atomic metallic $\mathrm{Cu}$ can improve the catalytic activity of graphite for the ORR without OER process. Since the hydrogenation of $\mathrm{O}_{2}$ molecule to form ${ }^{*} \mathrm{OOH}$ and the hydrogenation of ${ }^{*} \mathrm{OOH}$ to form $\mathrm{H}_{2} \mathrm{O}$ and atomic ${ }^{*} \mathrm{O}$, it can be happened spontaneously with a negative reactions energy, this step plays an extremely important role in ORR. It predicted that the reduction and oxidation potential for $\mathrm{U}_{\mathrm{ORR}}$ is $0.279 \mathrm{~V}$ and $\mathrm{U}_{\mathrm{OER}}$ is $2.76 \mathrm{~V}$, respectively. Our theoretical research is helpful for designing novel efficiency catalysts for fuel cells.

Acknowledgements Financial support comes from the China Scholarship Council (CSC: 201808440416) of China and Research and the Arts (HMWK) of the Hessen state in Germany. The Lichtenberg high performance computer is gratefully acknowledged, and we are also thankful to TU Darmstadt.

\section{Compliance with ethical standards}

Conflict of interest The authors declare that they have no conflict of interest.

\section{References}

1. Deng D, Novoselov KS, Fu Q et al (2016) Catalysis with twodimensional materials and their heterostructures. Nat Nanotechnol 11(3):218

2. Wu M, Cao C, Jiang JZ (2010) Light non-metallic atom ( $B, N, O$ and F)-doped graphene: a first-principles study. Nanotechnology 21(50):505202

3. Choi CH, Lim HK, Chung MW et al (2014) Long-range electron transfer over graphene-based catalyst for high-performing oxygen reduction reactions: importance of size, $\mathrm{N}$-doping, and metallic impurities. J Am Chem Soc 136(25):9070-9077

4. Lai L, Potts JR, Zhan D et al (2012) Exploration of the active center structure of nitrogen-doped graphene-based catalysts for oxygen reduction reaction. Energy Environ Sci 5(7):7936-7942 
5. Kurak KA, Anderson AB (2009) Nitrogen-treated graphite and oxygen electroreduction on pyridinic edge sites. J Phys Chem $C$ 113(16):6730-6734

6. Chen J, Wang X, Cui X et al (2014) Amorphous carbon enriched with pyridinic nitrogen as an efficient metal-free electrocatalyst for oxygen reduction reaction. Chem Commun 50(5):557-559

7. Ferrero GA, Fuertes AB, Sevilla M et al (2016) Efficient metal-free $\mathrm{N}$-doped mesoporous carbon catalysts for ORR by a template-free approach. Carbon 106:179-187

8. Ding W, Wei Z, Chen S et al (2013) Space-confinement-induced synthesis of pyridinic-and pyrrolic-nitrogen-doped graphene for the catalysis of oxygen reduction. Angew Chem 125(45):11971-11975

9. Luo Z, Lim S, Tian Z et al (2011) Pyridinic N doped graphene: synthesis, electronic structure, and electrocatalytic property. J Mater Chem 21(22):8038-8044

10. Jiang S, Sun Y, Dai H et al (2015) Nitrogen and fluorine dualdoped mesoporous graphene: a high-performance metal-free ORR electrocatalyst with a super-low $\mathrm{HO}_{2}$-yield. Nanoscale 7(24):10584-10589

11. Xiao $Y$, Wang J, Wang $Y$ et al (2019) A new promising catalytic activity on blue phosphorene nitrogen-doped nanosheets for the ORR as cathode in nonaqueous Li-air batteries. Appl Surf Sci 488:620-628

12. Bonaccorso F, Colombo L, Yu G et al (2015) Graphene, related twodimensional crystals, and hybrid systems for energy conversion and storage. Science 347(6217):1246501

13. Alves $\mathrm{HJ}$, Junior CB, Niklevicz RR et al (2013) Overview of hydrogen production technologies from biogas and the applications in fuel cells. Int J Hydrog Energy 38(13):5215-5225

14. Li Y, Gong M, Liang Y et al (2013) Advanced zinc-air batteries based on high-performance hybrid electrocatalysts. Nat Commun 4:1805

15. Qu K, Zheng Y, Dai S et al (2016) Graphene oxide-polydopamine derived N, S-codoped carbon nanosheets as superior bifunctional electrocatalysts for oxygen reduction and evolution. Nano Energy 19:373-381

16. Shin H, Choi W, Choi JY et al (2018) Doped graphene, method of manufacturing the doped graphene, and a device including the doped graphene: US Patent 9,887,020. 2018-2-6

17. Zhao A, Masa J, Xia W et al (2014) Spinel Mn-Co oxide in N-doped carbon nanotubes as a bifunctional electrocatalyst synthesized by oxidative cutting. J Am Chem Soc 136(21):7551-7554

18. Yin H, Zhang C, Liu F et al (2014) Hybrid of iron nitride and nitrogen-doped graphene aerogel as synergistic catalyst for oxygen reduction reaction. Adv Funct Mater 24(20):2930-2937

19. Bai X, Zhao E, Li K et al (2016) Theoretical insights on the reaction pathways for oxygen reduction reaction on phosphorus doped graphene. Carbon 105:214-223

20. Liang W, Chen J, Liu Y et al (2014) Density-functional-theory calculation analysis of active sites for four-electron reduction of $\mathrm{O} 2$ on Fe/N-doped graphene. ACS Catal 4(11):4170-4177

21. Lu Z, Xu G, He C et al (2015) Novel catalytic activity for oxygen reduction reaction on $\mathrm{MnN}_{4}$ embedded graphene: a dispersioncorrected density functional theory study. Carbon 84:500-508

22. Baran JD, Grönbeck H, Hellman A (2014) Analysis of porphyrines as catalysts for electrochemical reduction of $\mathrm{O} 2$ and oxidation of $\mathrm{H}_{2}$ O. J Am Chem Soc 136(4):1320-1326

23. Casalongue HS, Kaya S, Viswanathan V et al (2013) Direct observation of the oxygenated species during oxygen reduction on a platinum fuel cell cathode. Nat Commun 4:2817

24. Nørskov JK, Rossmeisl J, Logadottir A et al (2004) Origin of the overpotential for oxygen reduction at a fuel-cell cathode. J Phys Chem B 108(46):17886-17892

25. Zhang C, Zhang W, Zheng W (2019) Transition metal-nitrogencarbon active site for oxygen reduction electrocatalysis: beyond the fascinations of TM-N4. ChemCatChem 11(2):655-668
26. Fei $\mathrm{H}$, Dong J, Feng $\mathrm{Y}$ et al (2018) General synthesis and definitive structural identification of $\mathrm{MN}_{4} \mathrm{C}_{4}$ single-atom catalysts with tunable electrocatalytic activities. Nat Catal 1(1):63

27. Grillo ME, Finnis MW, Ranke W (2008) Surface structure and water adsorption on $\mathrm{Fe}_{3} \mathrm{O}_{4}$ (111): spin-density functional theory and onsite Coulomb interactions. Phys Rev B 77(7):075407

28. Mott NF (1969) Conduction in non-crystalline materials: III. Localized states in a pseudogap and near extremities of conduction and valence bands. Philos Mag 19(160):835-852

29. Henkelman G, Uberuaga BP, Jónsson H (2000) A climbing image nudged elastic band method for finding saddle points and minimum energy paths. J Chem Phys 113(22):9901-9904

30. Sheppard D, Xiao P, Chemelewski W et al (2012) A generalized solid-state nudged elastic band method. J Chem Phys 136(7):074103

31. Xiao Y, Liu Y, Frederick $N$ et al (2017) Ab initio study of the electronic structure, magnetic and dynamics properties in $\mathrm{LiMO}_{2}$ and $\mathrm{NaMO}_{2}(\mathrm{M}=\mathrm{V}$ and $\mathrm{Cr})$ as electrode cathode material for batteries. Solid State lon 307:26-34

32. Hafner J (2007) Materials simulations using VASP-a quantum perspective to materials science. Comput Phys Commun 177(1-2):6-13

33. Sun G, Kürti J, Rajczy P et al (2003) Performance of the Vienna ab initio simulation package (VASP) in chemical applications. $J$ Mol Struct THEOCHEM 624(1-3):37-45

34. Makov G, Payne MC (1995) Periodic boundary conditions in ab initio calculations. Phys Rev B 51(7):4014

35. Fomine S, Vargas SM, Tlenkopatchev MA (2003) Molecular modeling of ruthenium alkylidene mediated olefin metathesis reactions: DFT study of reaction pathways. Organometallics 22(1):93-99

36. Michaelides A, Hu P (2000) Insight into microscopic reaction pathways in heterogeneous catalysis. J Am Chem Soc 122(40):9866-9867

37. Michalkova A, Gorb L, Hill F et al (2011) Can the Gibbs free energy of adsorption be predicted efficiently and accurately: an M05-2X DFT study. J Phys Chem A 115(11):2423-2430

38. Simón L, Goodman JM (2011) How reliable are DFT transition structures? Comparison of GGA, hybrid-meta-GGA and meta-GGA functionals. Organ Biomol Chem 9(3):689-700

39. Vittadini A et al (2000) Formic acid adsorption on dry and hydrated TiO2 anatase (101) surfaces by DFT calculations. J Phys Chem B 104(6):1300-1306

40. Flyagina IS, Hughes KJ, Pourkashanian M et al (2014) DFT study of the oxygen reduction reaction on iron, cobalt and manganese macrocycle active sites. Int J Hydrog Energy 39(36):21538-21546

41. Hyman MP, Medlin JW (2006) Mechanistic study of the electrochemical oxygen reduction reaction on $\mathrm{Pt}(111)$ using density functional theory. J Phys Chem B 110(31):15338-15344

42. Calle-Vallejo F, Martínez Jl, Rossmeisl J (2011) Density functional studies of functionalized graphitic materials with late transition metals for oxygen reduction reactions. Phys Chem Chem Phys 13(34):15639-15643

43. Xiao Y, Zhang FC, Han Jl (2016) Synthesis, characterization and lithium-ion migration dynamics simulation of $\mathrm{LiFe}_{1-x} \mathrm{Tx}^{\mathrm{PO}_{4}}(\mathrm{~T}=\mathrm{Mn}$ $\mathrm{Co}$, La and $\mathrm{Ce}$ ) doping cathode material for lithium-ion batteries. Appl Phys A 122(11):980

44. Fazio G, Ferrighi L, Di Valentin C (2014) Boron-doped graphene as active electrocatalyst for oxygen reduction reaction at a fuel-cell cathode. J Catal 318:203-210

45. Li L, Wei ZD, Zhang Y et al (2009) DFT study of difference caused by catalyst supports in $\mathrm{Pt}$ and $\mathrm{Pd}$ catalysis of oxygen reduction reaction. Sci China Ser B Chem 52(5):571-578

Publisher's Note Springer Nature remains neutral with regard to jurisdictional claims in published maps and institutional affiliations. 